\title{
Prevalence of dental findings of children with celiac disease in Libya: a comparative study
}

\author{
Khadiga Herwis, Heballah Elturki, Ahmed Ali \\ Department of Pediatric Dentistry, Faculty of Dentistry, Benghazi University, Libya \\ Correspondence: Ahmed Ali. Address: Department of Pediatric Dentistry, Faculty of Dentistry, Benghazi University, \\ Libya. E-mail: ahsamu@utu.fi
}

Received: September 21, 2014

Accepted: October 15, 2014

Online Published: October 24, 2014

DOI : $10.5430 /$ crcp.v2n1p61

URL: http://dx.doi.org/10.5430/crcp.v2n1p61

\section{Abstract}

Background and objectives: Celiac disease is a disease affecting the digestive system whereby the patient is unable to tolerate gluten-containing food. The aims of this study were to study the prevalence of dental defects and oral hygiene status of a group of celiac disease patients in Benghazi.

Materials and methods: A group of celiac disease patients ( $\mathrm{n}=40$ \& Male: Female ratio is 1:2.4 \& age range 3-19 years, mean 10 years, $S D \pm 4.8$ ) were recruited from Benghazi Pediatric Hospital where they had already been diagnosed in gastroenterology units at private clinics. The patient's dental status was assessed through measuring their Decayed, Missing and Filled Teeth index (DMFT), oral hygiene index (OHI) and CPITN using disposable mouth mirrors, explorers and periodontal probes. Descriptive statistics was applied to give a picture about the oral hard and soft tissue prevalence this group of patients.

Results: Descriptive statistics of the celiac sample showed that $29(72.5 \%)$ had enamel hypoplastic defects. The mean and $S D$ values for DMFT, CPITN and OHI were measured (DMFT: $4.5 S D \pm 4.7 \&$ CPITN: $0.8 S D \pm 0.5$; and OHI: $1.1 S D \pm$ 0.7). Besides, only two patients (6.4\%) reported a history of oral ulceration during the course of their therapy. Healthy controls showed comparative values, being less in only OHI, while they were slightly more in DMFT and CPITN.

Conclusion: This is a cross-sectional clinical survey showing that patients with celiac disorder should be expected to have higher prevalence of defective incisor teeth, which makes their front teeth liable to traumatic fracture. The presence of frequent soft tissue ulcers in their mouths might indicate a warning sign of the possibility to develop the disease and thus urge the child's parents or guardians to consult a physician to confirm or negate the suspicion.

\section{Key words}

Celiac disease, Comparative study, Enamel hypoplasia

\section{I ntroduction}

Celiac disease (also called gluten-sensitive enteropathy or dependent disorder of the small intestine) is a multisystemic disorder that occurs in genetically-predisposed individuals and is associated with other autoimmune diseases ${ }^{[1]}$. In its essence, celiac disease is considered as an autoimmune enteropathy owing to the complex immune-mediated reaction to specific gluten-peptides ${ }^{[2]}$ found in wheat and other grain products such as rye, barley, which, in celiac patients, cause 
villous atrophy and malabsorption. When gluten-products come in contact with the intestinal tissue, an unbalanced complex immune response is triggered leading to damage of the intestinal mucosa. The diagnosis of celiac disease is traditionally conducted by means of histopathological examination of biopsies taken from the intestinal tissue; and sometimes by noticing the suspected patient in case their symptoms subside e.g., diarrhea and weight loss, after they are given gluten-free diet. Children with celiac disease are prone to develop other autoimmune diseases such as type I diabetes mellitus; which also reflects the reverse relation: diabetic children should be tested for celiac disease. Patients who are likely to develop celiac disease have a higher possibility of IgA deficiency; therefore their total IgA should be measured ${ }^{[3]}$. The number of detected cases has increased recently due to general awareness of the disease and introducing sophisticated methods for its screening and diagnosis. Whenever being in suspicion of having celiac disease, a detailed medical history (especially pertaining to diet), physical examination, serology, upper endoscopy and histopathological analysis of multiple biopsies of the duodenum should be pursued to confirm the diagnosis ${ }^{[4]}$. Care should be taken not to confuse celiac disease with other forms of gluten sensitivity conditions in which the patient complains from symptoms similar to those of celiac disease but without showing the serologic or histological features of the latter ${ }^{[5]}$. These conditions have been termed non-celiac gluten sensitivity (NCGS).

Oral mucosal lesions are found in patients with celiac disease. These lesions range from glossitis, recurrent aphthous ulcer, stomatitis as well as burning mouth syndrome. Enamel abnormalities (such as enamel hypoplasia) and delayed eruption of teeth are commonly encountered in celiac patients due to malabsorption of calcium. The aim of our study was to evaluate the prevalence of the different oral manifestations, related to soft and hard oral tissues, in celiac patients in Benghazi and compare them with a sample of healthy counterparts.

\section{Subjects and methods}

In this study, 40 patients affected with celiac disease and 30 healthy subjects were recruited. The celiac disease patients (age range 3-19 years; Mean: 11 years) had already been diagnosed in private clinics and GIT units in public hospitals before they were recruited using the registration data at Benghazi Pediatric Hospital-the main hospital for child patients in Benghazi. The healthy subjects (age range 5-16 years, Mean: 12 years) were recruited from four public schools in different zones of the city in order to match for the geographical location of their counterpart patients. They were also matched for age and gender (see Figure 1). For the clinical examination, an experienced dentist examined the patients and healthy subjects and took down all the findings relevant to the study. She conducted the clinical examination using disposable mouth mirrors, explorers and periodontal probes under natural light. To ensure proper visualization, in every examination setting, each child was seated in a chair facing the window to allow for maximum level of illumination. Verbal consent was obtained from the guardian of each child selected for the study. Both groups were screened for the presence of dental hypoplasia, mainly in the anterior teeth and their presence was categorized into the four grades suggested by Aine ${ }^{[6]}$. A brief description of these four grades is summarized (see Table 1).

Figure 1. The relative gender proportion in celiac disease patients and healthy subjects

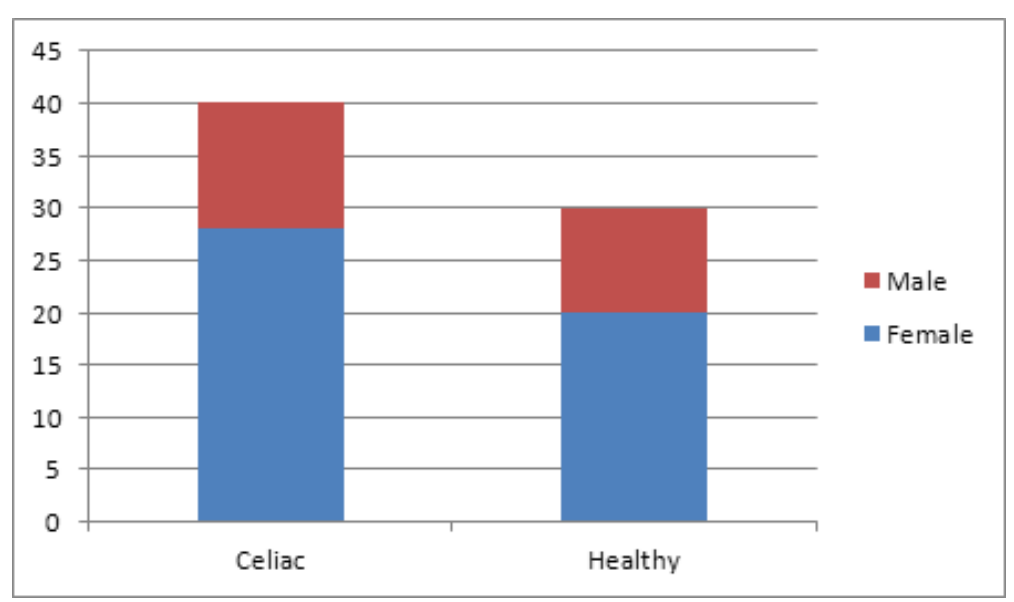

ISSN 2331-2726 E-ISSN 2331-2734 
Table 1. Classification of the dental hypoplastic defects (modified from Bossu et al.)

\begin{tabular}{ll}
\hline Grade & Description \\
\hline 0 & No defects \\
I & The defects are manifested as changes in color of enamel \\
II & Slight structural defects with typical horizontal grooves \\
III & Evident structural defects with horizontal grooves and large vertical pits \\
IV & Severe structural defects where the shape of the tooth may be changed \\
\hline
\end{tabular}

Decayed, Missing and Filled Teeth index (DMFT), CPITN and oral hygiene index (OHI) were also calculated. Statistical analysis was used where matching of age difference between the two groups was assessed by chi square. The statistical significance, i.e., $p$ value, was set at $<.05$.

\section{Results}

Clinical examination of the oral cavities of celiac children showed that the majority had enamel hypoplasia of the upper anterior teeth, mostly the central incisors in the middle region (see Figure 2). In some patients, these hypoplastic defects were associated with tooth fracture (see Figure 3).

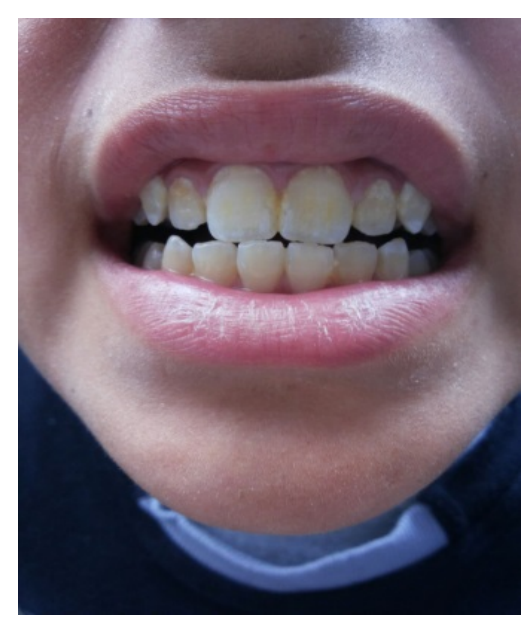

Figure 2. Enamel hypoplasia in the middle third of upper incisor teeth of a child with celiac disease

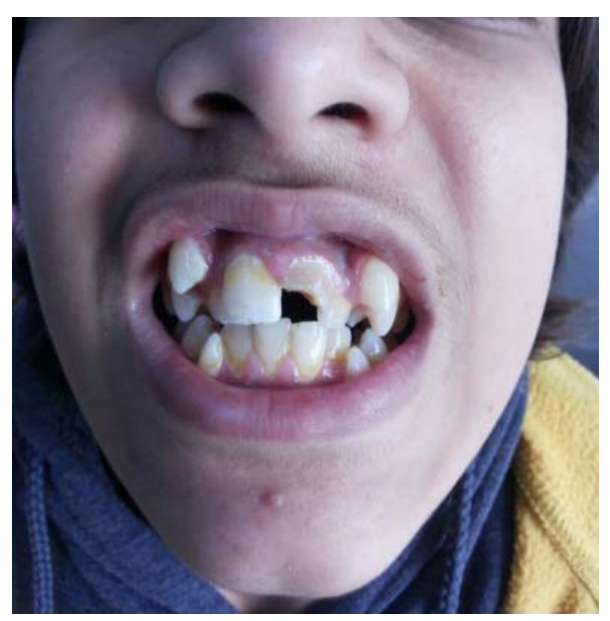

Figure 3. Fracture of upper left central incisor in a child with celiac disease

We have selected the healthy group in such a way that neither gender nor age differences would have any influence on the dental findings. For example, in terms of gender distribution between the two groups the chi square test revealed no significant difference $\left(\chi^{2}=0.08, p=.7\right)$. Out of 40 celiac patients, $29(72.5 \%)$ had enamel hypoplasia ranging from class I to class IV, where 23 showed class I, 5 showed class II, and only one showed class IV (see Figure 4). Thus the majority of dental hypoplasia in celiac patients belonged to class I (see Figure 3).

In contrast to the celiac patients, none of the healthy controls showed such hypoplastic defects, and that was highly significant using chi square test $\left(\chi^{2}\right.$ value $\left.=37 \& p<.001\right)$ (see Table 2$)$.

Table 2. The difference in dental hypoplasia between celiac patients and healthy subjects

\begin{tabular}{lll}
\hline Sample & Hypopolasia & No hypoplasia \\
\hline Celiac & 29 & 11 \\
Healthy & 0 & 30 \\
\hline
\end{tabular}

Note. $\chi^{2}=37 ; p<.001$ 
Figure 4. The distribution of grades of enamel hypoplasia among the celiac disease patients. Notice that no grade III was found.

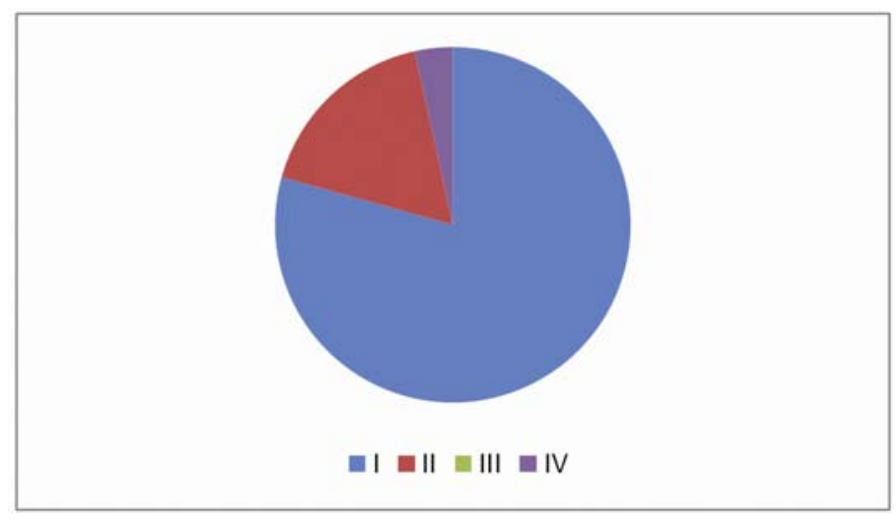

As for the DMFT, both groups showed comparatively high levels of scores where healthy controls were found to express a slightly higher value (Mean: 5.6, Median: 4.5) than the celiac patients (Mean: 4.7, Median: 4) Using Mann-Whitney $U$ test, no statistical significance was found when the values were considered individually $(p=.6)$.

The CPITN index showed a slight variation between celiac patients (Mean: 0.8, Median: 1, Mode: 1) and healthy controls (Mean: 1.1, Median: 1, Mode: 1). Using Mann-Whitney $U$ test, the difference was not significant.

The oral hygiene index (plaque index and calculus index; calculated separately then summed together) was slightly higher in celiac patients (Mean: 1.5, Median: 1.3, Mode: 1) compared to healthy controls (Mean: 1.3, Median: 1.3, Mode: 1).

\section{Discussion}

The present study aimed to compare the dental findings of patients with celiac disease with healthy counterparts. Celiac disease is an immunological disorder emanating from sensitivity of the intestinal mucosa to gluten or prolamine, and thus affects primarily the intestinal tissue ${ }^{[7]}$ in genetically predisposed people ${ }^{[8]}$. Patients affected by celiac disease have a broad range of clinical manifestations due to autoantibody response which is triggered by exposing the intestinal tissue to gluten ${ }^{[9]}$. Beside the systemic symptoms, extra-intestinal signs of the disease involve the oral cavity at both the hard and soft tissue levels ${ }^{[10]}$.

The concomitant increase in risk of dental developmental defects found in celiac disease patients was suggested to be related to the presence of HLA-DR3 antigen ${ }^{[11]}$. In addition, the hard tissue anomalies seem to stem from two roots: either hypocalcemia leading to calcium malabsorption ${ }^{[12]}$; or autoimmune reaction against enamel-forming cells (ameloblasts) ${ }^{[13,14]}$. However, it remains a limitation of our study that no HLA-associated antigens were screened in our celiac patients. Oral ulceration is among the main dental manifestations of celiac disease; these ulcers have been traditionally considered as aphthous-like lesions ${ }^{[15]}$.

The prevalence of $\mathrm{CD}$ in Europe is about $1 \%$ and it is hardly found in Asians or Blacks ${ }^{[16]}$; while in the North Africa (including Libya) it has been estimated to range from $5 \%$ to $16 \%{ }^{[17-19]}$. A study from Saudia Arabia has shown that children with type 1 diabetes tend to suffer from celiac disease (11.3\%) more than their non-diabetic peers ${ }^{[20]}$.

All the dental hypoplastic defects of celiac patients were found exclusively in the anterior teeth, mainly the incisors; and that might be attributed to the corresponding phase of the active course of the disease with the stage of odontogenesis of the involved teeth ${ }^{[21]}$. In other words, the early calcification of anterior teeth coincides with the digestive and absorptive imbalances induced by the presence of gluten in the diet consumed by diseased children. Once the disease is diagnosed, the gluten will be removed from the diet and thus no malabsorption is encountered, thereby leading to cease of the defects of teeth in the active phase of development. 
The present study has shown that celiac children have significantly higher enamel hypoplasia than the non-celiac group.

Apparently due to the hypoplastic nature of anterior teeth in celiac patients, some teeth sustained fracture due to trauma (see Figure 3). This developmental defect should enhance them to adapt more care not to expose the anterior teeth to physical injuries. Our findings seem to be in accordance with those of Aguirre et al. ${ }^{[21]}$ and Fulstow ${ }^{[22]}$ where their DMFT of the healthy controls were slightly higher than celiac patients; they attributed this difference to the strict type of low-cariogenic food given to celiac children.

It was also interesting to find that healthy control children had higher CPITN value, which reflects the health of their gingival tissue. It seems that celiac children are taken care of by their parents (or guardians) in terms of providing them with strictly-scheduled diets and performing oral hygiene measures.

In summary, the main dental manifestations that celiac patients tend to suffer from are enamel hypoplasia in their incisor teeth as well as aphthous-like ulcers affecting their oral soft tissues.

\section{References}

[1] Radlovic N. Celiac disease. Srpski arhiv za celokupno lekarstvo. 2013; 141(1-2): 122-6. PMid: 23539923. http://dx.doi.org/10.2298/SARH1302122R

[2] Francavilla R., et al. Clinical, Serologic, and Histologic Features of Gluten Sensitivity in Children. The Journal of pediatrics. 2013. PMid: 24252792.

[3] Wang N., L Hammarstrom. IgA deficiency: what is new? Current opinion in allergy and clinical immunology. 2012; 12(6): 602-8. PMid: 23026772. http://dx.doi.org/10.1097/ACI.0b013e3283594219

[4] Friedt M., S Welsch. An update on pediatric endoscopy. European journal of medical research. 2013; 18(1): 24 . PMid: 23885793. http://dx.doi.org/10.1186/2047-783X-18-24

[5] Lundin KE, A Alaedini. Non-celiac gluten sensitivity. Gastrointestinal endoscopy clinics of North America. 2012; $22(4): 723-34$. PMid: 23083989. http://dx.doi.org/10.1016/j.giec.2012.07.006

[6] Aine L. Dental enamel defects and dental maturity in children and adolescents with coeliac disease. Proceedings of the Finnish Dental Society. Suomen Hammaslaakariseuran toimituksia. 1986; 82 Suppl 3: 1-71. PMid: 3725749.

[7] Datta Gupta S. Pathology of celiac disease: a brief review. Tropical gastroenterology: official journal of the Digestive Diseases Foundation. 2013; 34(4): 207-26. PMid: 25046883. http://dx.doi.org/10.7869/tg.138

[8] Piscaglia AC. Intestinal stem cells and celiac disease. World journal of stem cells. 2014; 6(2): 213-29. PMid: 24772248. http://dx.doi.org/10.4252/wjsc.v6.i2.213

[9] Fasano A., C Catassi. Clinical practice. Celiac disease. The New England journal of medicine. 2012; 367(25): 2419-26. PMid: 23252527. http://dx.doi.org/10.1056/NEJMcp1113994

[10] Cheng J, et al. The association between celiac disease, dental enamel defects, and aphthous ulcers in a United States cohort. Journal of clinical gastroenterology. 2010; 44(3): 191-4. PMid: 19687752. http://dx.doi.org/10.1097/MCG.0b013e3181ac9942

[11] Mariani P, et al. Coeliac disease, enamel defects and HLA typing. Acta paediatrica. 1994; 83(12): 1272-5. PMid: 7734869. http://dx.doi.org/10.1111/j.1651-2227.1994.tb13014.x

[12] Smith DM and J Miller. Gastro-enteritis, coeliac disease and enamel hypoplasia. British dental journal. 1979; 147(4): 91-5. PMid: 295229. http://dx.doi.org/10.1038/sj.bdj.4804290

[13] Maki M, et al. Dental enamel defects in first-degree relatives of coeliac disease patients. Lancet. 1991; 337(8744): 763-4. http://dx.doi.org/10.1016/0140-6736(91)91375-5

[14] Bossu M, et al. Enamel hypoplasia in coeliac children: a potential clinical marker of early diagnosis. European journal of paediatric dentistry: official journal of European Academy of Paediatric Dentistry. 2007; 8(1): 31-7.

[15] Femiano F, et al. Oral aphthous-like lesions, PFAPA syndrome: a review. Journal of oral pathology \& medicine: official publication of the International Association of Oral Pathologists and the American Academy of Oral Pathology. 2008; 37(6): 319-23. http://dx.doi.org/10.1111/j.1600-0714.2008.00634.x

[16] Collin P, et al. High incidence and prevalence of adult coeliac disease. Augmented diagnostic approach. Scandinavian journal of gastroenterology. 1997; 32(11): 1129-33. PMid: 9399394. http://dx.doi.org/10.3109/00365529709002992 
[17] Boudraa G, et al. Prevalence of coeliac disease in diabetic children and their first- degree relatives in west Algeria: screening with serological markers. Acta paediatrica. 1996; 412: 58-60. PMid: 8783762. http://dx.doi.org/10.1111/j.1651-2227.1996.tb14254.x

[18] Mankai A, et al. Screening by anti-endomysium antibodies for celiac disease in Tunisian children with type 1 diabetes mellitus. Gastroenterologie clinique et biologique. 2007; 31(5): 462-6. http://dx.doi.org/10.1016/S0399-8320(07)89413-9

[19] Ashabani A, et al. The prevalence of coeliac disease in Libyan children with type 1 diabetes mellitus. Diabetes/metabolism research and reviews. 2003; 19(1): 69-75. PMid: 12592646. http://dx.doi.org/10.1002/dmrr.333

[20] Al-Hussaini A, et al. High prevalence of celiac disease among Saudi children with type 1 diabetes: a prospective cross-sectional study. BMC gastroenterology. 2012; 12: 180. PMid: 23259699. http://dx.doi.org/10.1186/1471-230X-12-180

[21] Aguirre JM, et al. Dental enamel defects in celiac patients. Oral surgery, oral medicine, oral pathology, oral radiology, and endodontics. 1997; 84(6): 646-50. http://dx.doi.org/10.1016/S1079-2104(97)90367-X

[22] Fulstow ED. Incidence of dental caries in coeliac children. Archives of disease in childhood. 1979; 54(2): 166. PMid: 434897. http://dx.doi.org/10.1136/adc.54.2.166-b 